GA-A21532

UC-420

\title{
DIII-D IN-VESSEL PORT COVER AND SHUTTER ASSEMBLY FOR THE PHASE CONTRAST INTERFEROMETER
}

\author{
by \\ R.D. PHELPS
}

Prepared under

Contract No. DE-AC03-89ER51114

for the U.S. Department of Energy

GENERAL ATOMICS PROJECT 3466

JANUARY 1994 


\section{INTRODUCTION}

The entire outer wall of the DIII-D vacuum vessel interion is covered with a regular array of graphite tiles. Certain of the diagnostic ports through the outer vessel wall contain equipment which is shielded from the plasma by installing port covers designed to withstand energy deposition. If the diagnostic contained in the port must communicate with the vessel volume, a shutter assembly is usually provided. In the ports at 285 degrees, $\mathrm{R}+1$ and $\mathrm{R}-1$, interferometer mirrors have been installed to provide a means for transmitting a large diameter $\mathrm{CO}-2$ laser beam through the edge of the plasma. To protect the mirrors and other hardware contained in these ports, a special protective plate and shutter arrangement has been designed. This report describes the details of design, fabrication, and installation of these protective covers and shutters. (Design details of the installation are shown on GA Drawing \#4-3249-0012. See Appendix A). 


\section{DESIGN}

The 285 degree $R+1$ and $R-1$ port interfaces with the vessel wall are configured in the form of a 12-inch square with rounded 3-inch radius corners. (See Appendix A for representative drawings). The mirror mount and support hardware for the interferometer installed in these ports protrudes about 1-inch into the vessel volume beyond the Inconel vessel wall, but remains behind the plane of the outer wall tiles. To develop the necessary protection for the interferometer hardware, a 0.25 -inch thick Inconel 600 plate was fabricated to fit the port opening. This plate is covered with a $0.3^{3} / 5$-inch thick sheet of graphite composite material. (Trade name $=$ "K-Karb." Technical data on this material can be found in Appendix B). The composite is known technically as a carbon-carbon fiber reinforced graphite. A sheet of graphoil interface material is placed between the plate and the graphite composite to provide the flexibility needed to accommodate any surface irregularities between the Inconel plate and the composite. When installed in the vessel, the surface of the protective cover is positioned approximately 0.1 to 0.2 inches behind the plane of the outer wall tile array.

The three-inch diameter CO-2 laser beam is reflected by mirror systems in the $\mathrm{R}+1$ and R-1 ports such that the beam passes through the edge of the plasma from one port to the other in a vertically downward direction (See Fig. 1). This arrangement requires that there be an opening in each of the two port covers. As with most of the mirror and window systems in the tokamak, a shutter mechanism is used to open a path for the laser beam when the diagnostic is operating, and to remain closed for protection during periods when the diagnostic is not operating. 


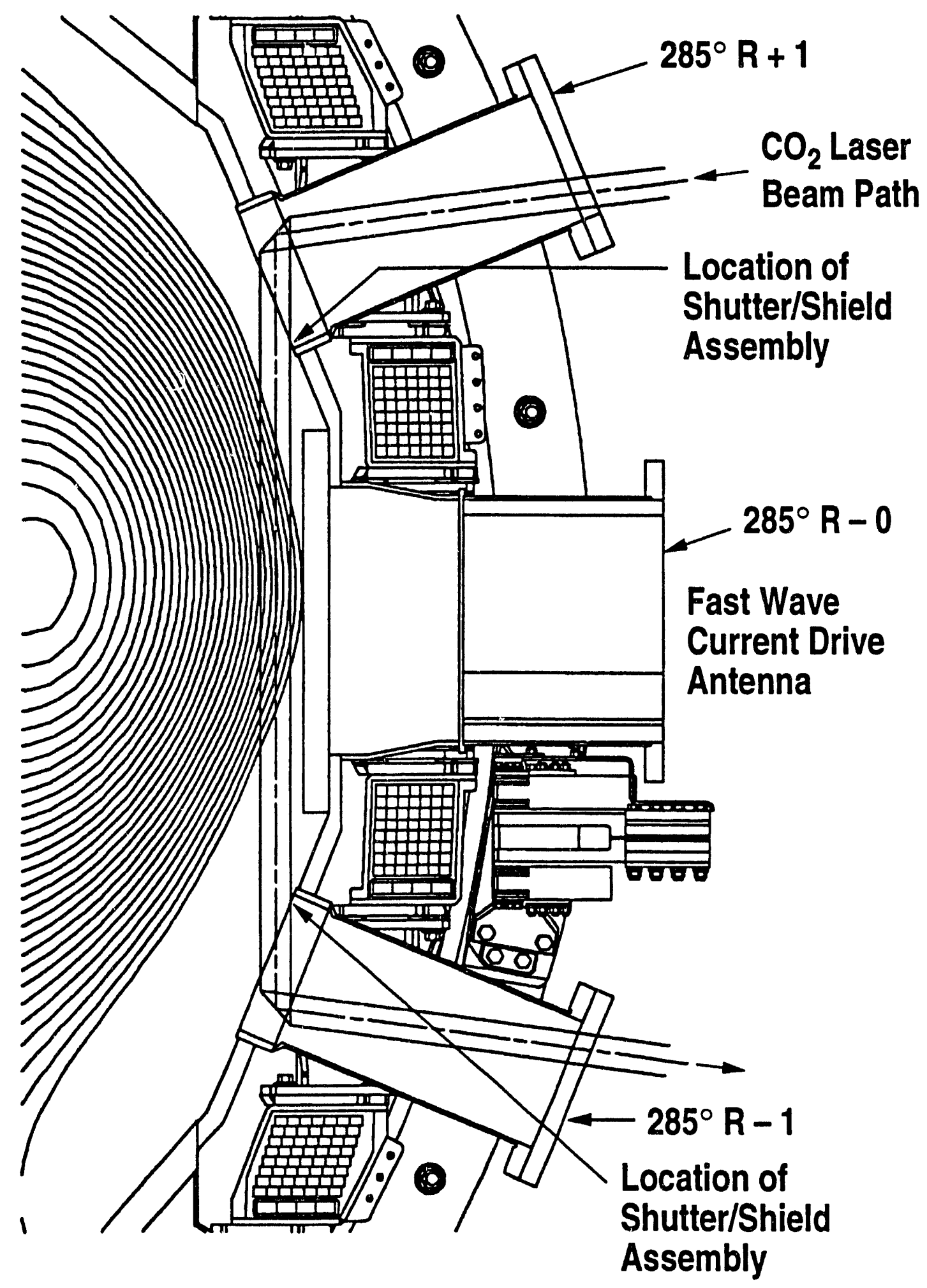

Fig. 1. Interferometer beam plate through DIII-D. 
The shutter arrangement designed for this application is driven by an air cylinder operating on a linear feedthrough mechanism to transfer motion into the vacuum vessel (See Fig. 2). The feedthrough provides a one-inch stroke to move a push rod which in turn operates the shutter actuator hardware attached to the port cover assembly. The shutter itself moves through an arc of 90 degrees. When open, the space available for the laser beam forms a square about four inches on a side leaving ample room around the edges for unrestricted passage of the three-inch diameter beam. However, since the beam passes very close to one edge of the port, the small graphite wall tile along this edge is not installed (See photo, Fig. 3). This creates an open space because the cover plate is positioned about two inches above the plane of the vessel wall at the point where the graphite wall tile is misssing. That edge of the shutter is affixed with an Inconel skirt which effectively closes off the space between the vessel wall and the protective plate when the shutter is closed.

Since the shutter drive mechanism operates in the hard vacuum of the tokamak, there exists the problem of friction between the moving parts. Historically, where applicable, and considering loads and operating duty cycles, silver plating has been specified for use on the bearing surfaces of the moving parts. This design feature has been used at several places in the machine vacuum where friction between surfaces could become a problem. Accordingly, both the push rod connection and the shutter hinge are designed with $0.25-$ inch diameter rods which have been silver plated to approximately three mils to minimize any frictional effects which might develop. 


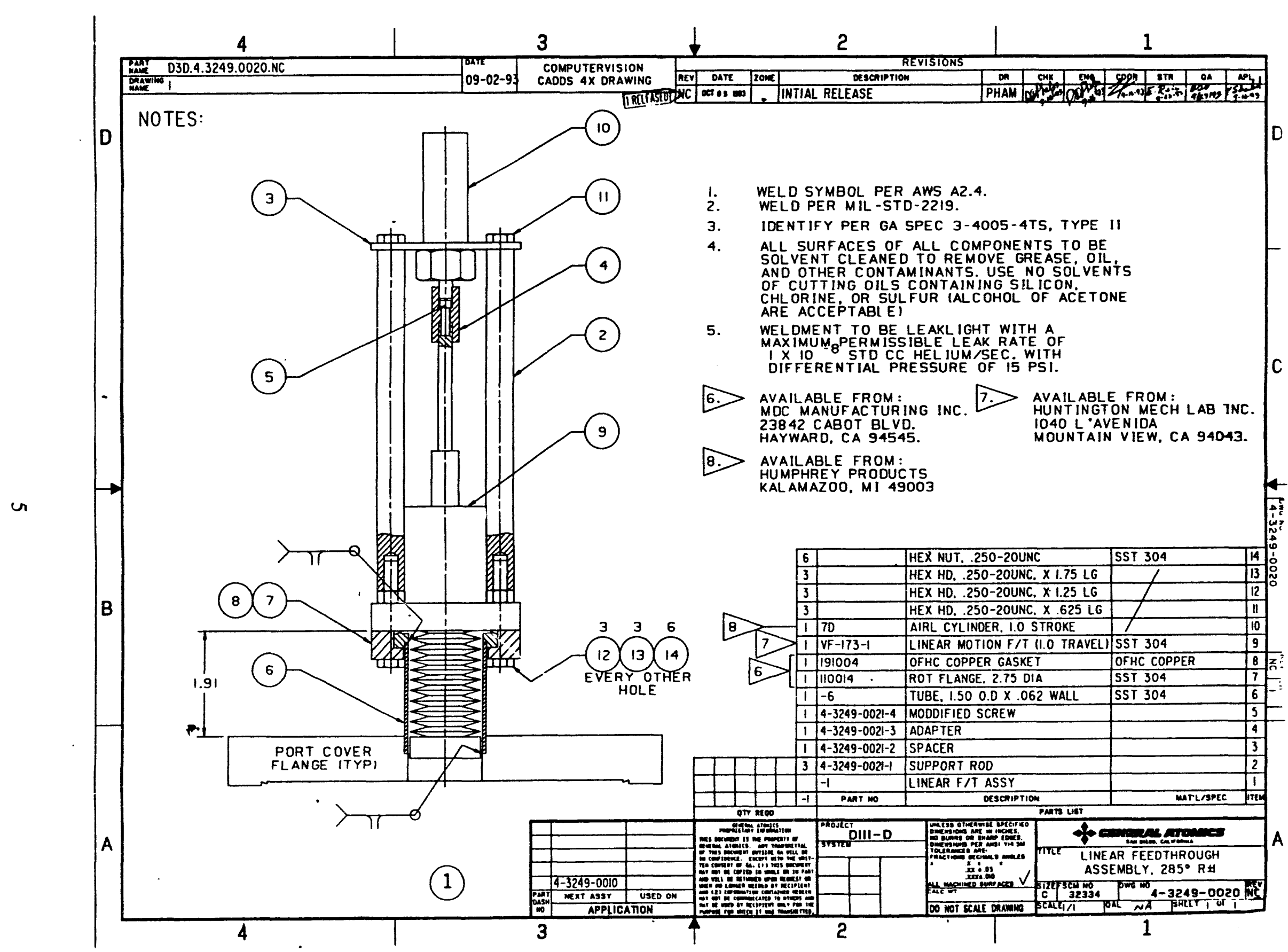

Fig. 2. Linear feedthrough assembly, $285^{\circ} R+1$ 


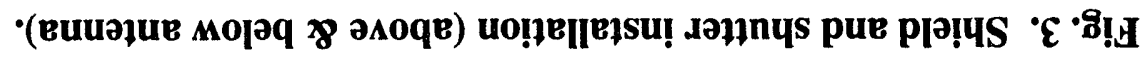

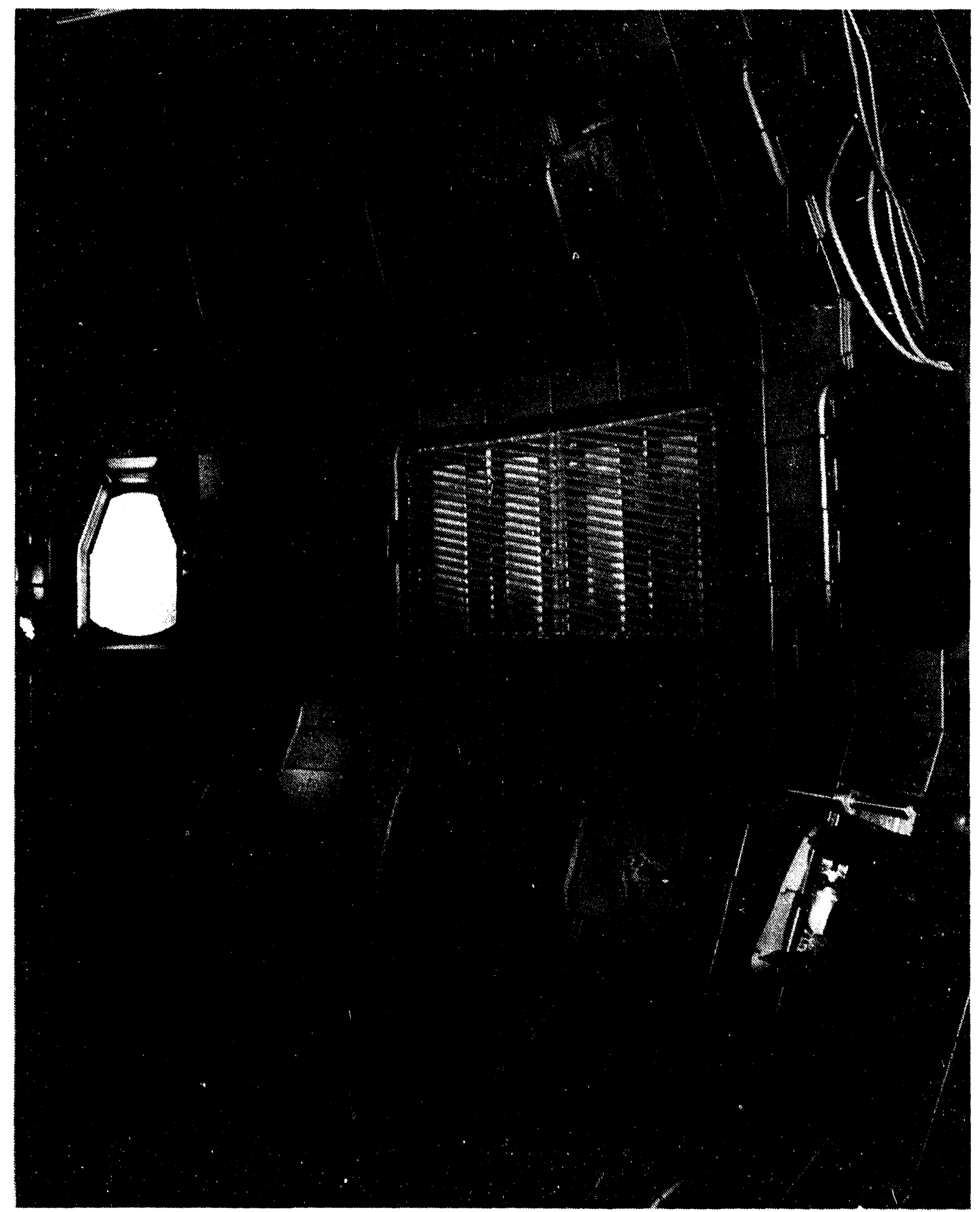




\section{ENGINEERING}

Diagnostic ports which contain hardware and equipment items must be protected from energy deposition which could cause damage to the diagnostic. In most cases, this protection is afforded by installing a custom designed in-vessel port cover. The port covers for the $\mathrm{R}+1$ and $\mathrm{R}-1$ ports at 285 degrees are fabricated from Inconel alloy 600. This material is similar to the primary vessel material which is Inconel alloy 625. A stress analysis was performed on the plate to determine forces and loads due to a 3.0 megamp disruption applied dynamically as a three millisecond pulse.* Plate stresses of approximately 2000 psi were calculated. However, an inward pressure load of 51 psi also develops during this disruption scenario which required the use of 1/4-inch thick material in the support legs for the cover to prevent local overstressing along the edges of the legs. The Inconel plate is attached to the vessel by bolting to a series of four 0.375 -inch diameter studs welded to the port frame. The anchor nuts on these studs are torqued to 35 foot-pounds.

Generally, any plasma facing component installed in the vessel is required to be fabricated of Inconel to eliminate perturbations due to differences in magnetic properties of these materials. These surfaces are also subject to large energy depositions from time to time during certain operating conditions. The strength and elevated temperature properties of Inconel alloys make them well suited to the application.

To obtain the same degree of protection as that afforded by the graphite wall tiles, the port covers are covered with a layer of carbon-carbon fiber graphite composite material (K-Karb). As with the wall tiles, the carbon-carbon composite is installed over a graphoil sheet to obtain good thermal contact and to provide for surface accommodation. The

\footnotetext{
*Memo, E. Reis to R.D. Phelps, "Stress Analysis of Port Covers at 285 Degrees," October 9, 1992.
} 
composite is divided into four separate pieces, each individually attached to the Inconel cover using a pair of bolts. The shutter itself is covered by a single piece of composite. An arrangement of several pieces is used to decrease the magnitude of eddy currents which develop in the graphite composite material during operation thus reducing the torque and loads applied to the composite material and its supporting attachments.

The five pieces of composite are attached to the Inconel plate using bolts fabricated from the same carbon-carbon material (K-Karb). These bolts are 0.375-inch diameter, 16 threads per inch, and 1.00 inch long. Pull tests on these bolts have shown them to be capable of resisting an axial force of more than one thousand pounds without failure (See Fig. 4 for results of a tensile test). The composite pieces are drilled and tapped with internal threads to permit insertion of the bolts through the Inconel plate for tightening into the composite material. To allow for thermal expansion and lateral movement between the materials, the heads of the carbon-carbon bolts are tightened against a pair of belleville spring washers oriented in a nested fashion. The bolts are tightened just enough to obtain a prescribed squeeze on the spring washers of 0.020 inch. (Fig. 5 shows the results of force-deflection tests on these washers). This compression creates a preload of 260 pounds which is sufficient to maintain good thermal contact after the expected amount of long term creep develops in the graphoil interface material. After the bolts have been tightened to the proper preload, they are fixed in position by spot welding a thin stainless steel strip over the square bolt head.

NOTE: Although these bolts are quite adequate in terms of tensile strength, they can be twisted to a torsional failure rather easily during installation. It was very important to limit the torque applied to prevent such torsional failure. During assembly, a means was developed to apply an axial load to the bolts to achieve the desired amount of deflection in the spring washer, which then allowed the bolt to be turned down as required to hold the deflection while minimizing the torque applied. In future applications of this nature, it is recommended that a common stainless steel bolt be utilized to prevent inadvertent 
overtorquing. The effects of differential thermal expansion are not significant in the radial direction, although the stainless steel expands slightly more than the K-Karb. Axially, there would be a temporary loss of approximately $30 \%$ in the spring washer preload during a transient to $500^{\circ} \mathrm{C}$.

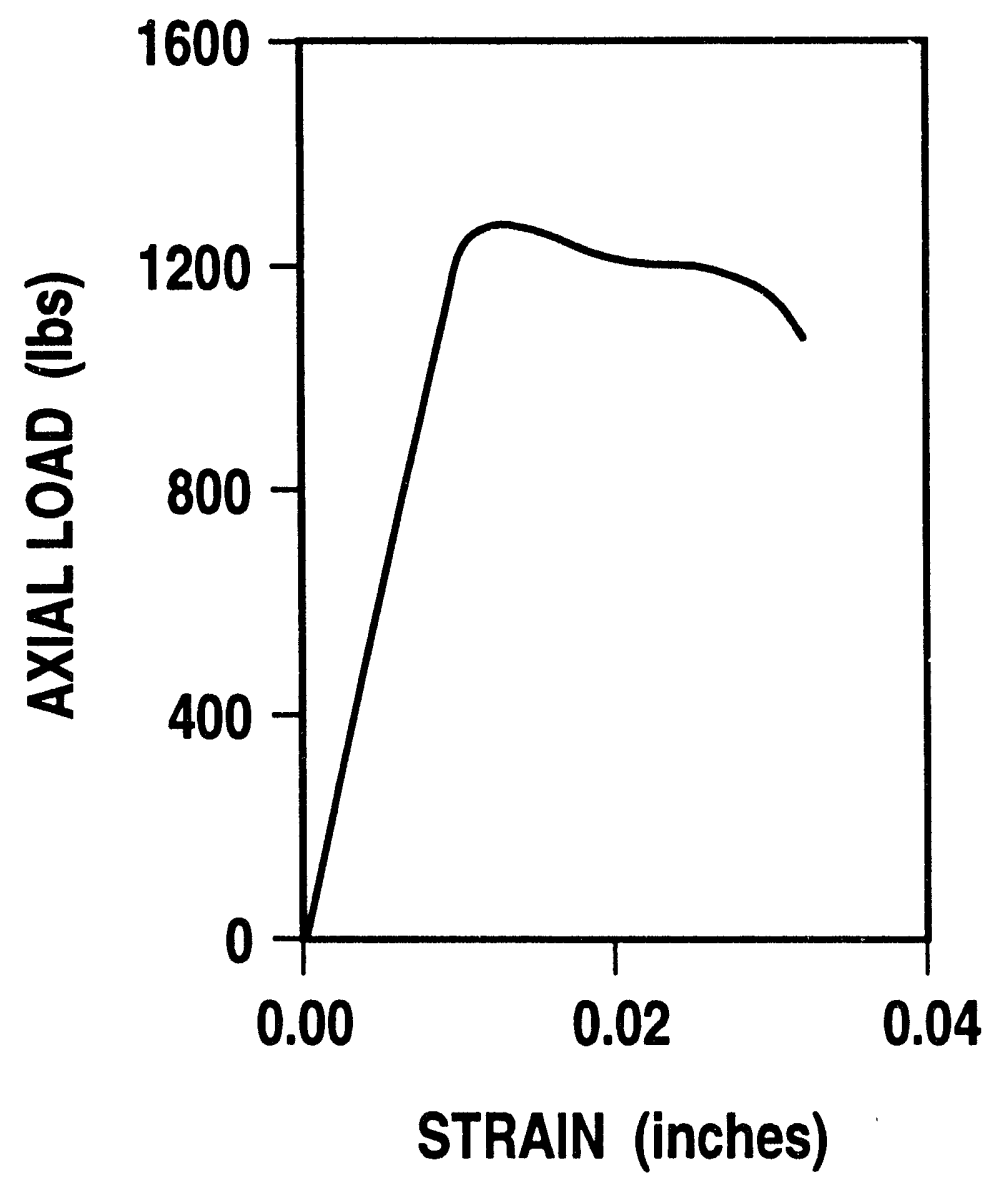

Fig. 4. Tensile load test on $3 / 8$ inch diameter K-Karb bolt. 


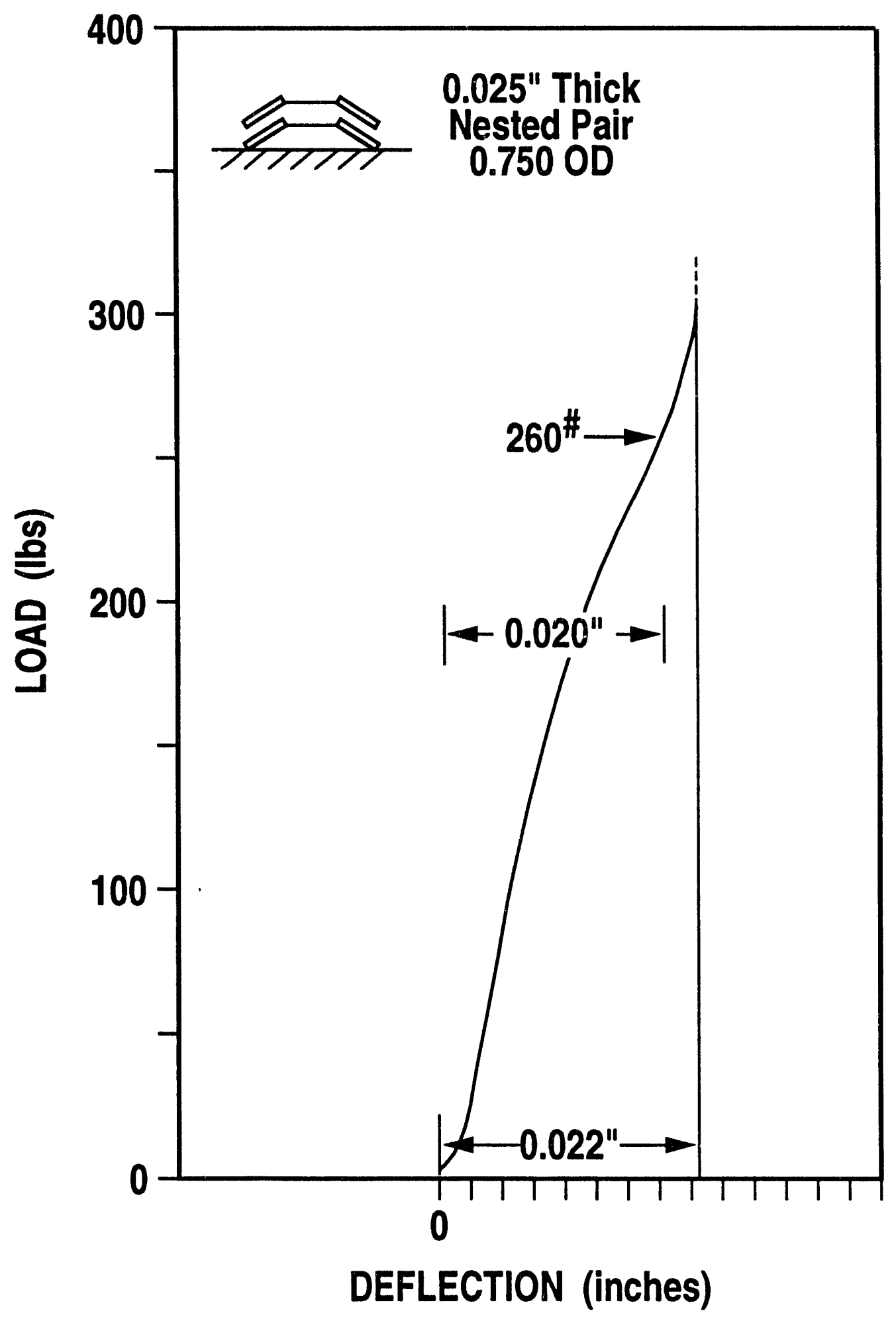

Fig. 5. Performance of Belleville spring washers. 


\section{INSTALLATION}

To obtain a proper fit with the new wall tiles, in-vessel measurements were made to verify spatial relationships. The peripheral graphite tiles around each of the two ports were installed on their respective graphoil sheets. The distance between the face of the port and the top of the tiles was then measured carefully at several locations. From these data, the correct height of the Inconel support legs could be established. Due to the conical shape of the vessel in the $\mathrm{R}+1$ and $\mathrm{R}-1$ areas, the port cover assumes the shape of a trapezoid. Measurements were taken between several points to establish the exact shape of the overall port cover. Following these measurements, final machining of the parts was completed and the support legs welded to the plates.

Attachment of hardware to the vessel walls is usually accomplished using a welded stud 0.92 -inches long fabricated of 316 stainless steel. It contains a 3/8-24 full length thread, plus a small 0.050 -inch spike in the center of the welding end to allow a concentrated arc to be drawn during the stud welding process. Normally, these studs are welded to the vessel wall using a stud gun. However, in this case, the studs were welded to the port frame using a conventional shielded arc process. A template was prepared to assist with proper location since it was imperative that the studs be welded in a manner to assure that the cover plate assembly would be positioned evenly relative to the surrounding tiles (See the Shield Plate Installation Procedure, Appendix C). Due to the geometry of the installation, the standard 0.92 -inch long stud was shortened to 0.70 -inch, the stud welding spike was removed, and a small bevelled weld prep was added to the

outer edge of the welded end of the stud. After the studs were welded, the template was removed. 
The composite tiles were attached to both the Inconel plate and to the shutter door. The completed shutter was assembled to the plate by inserting the silver plated hinge pin and securing it with a cotter key. The integrated cover plate and shutter assembly was placed on the port and bolted down. The nuts were then torqued to 35 foot-pounds, after which the peripheral wall tiles were installed.

Initial connections were then made between the shutter operating push rod and the shutter actuator to test for correct operation. The push rod attachment hardware is designed with a threaded connection to afford positioning capability. Adjustments were made to obtain firm shutter closure while achieving a full opening stroke. 


\section{APPENDIX A}

\section{REFERENCE DRAWINGS FOR THIS INSTALLATION:}

1. Vessel Port Arrangement, Dwg. \# 4-2107-0040, Rev. C, October 1984.

2. Shield Assembly, 285 degrees, R \pm 1, Dwg. \#3249-0012, Rev. A, June 1993. 


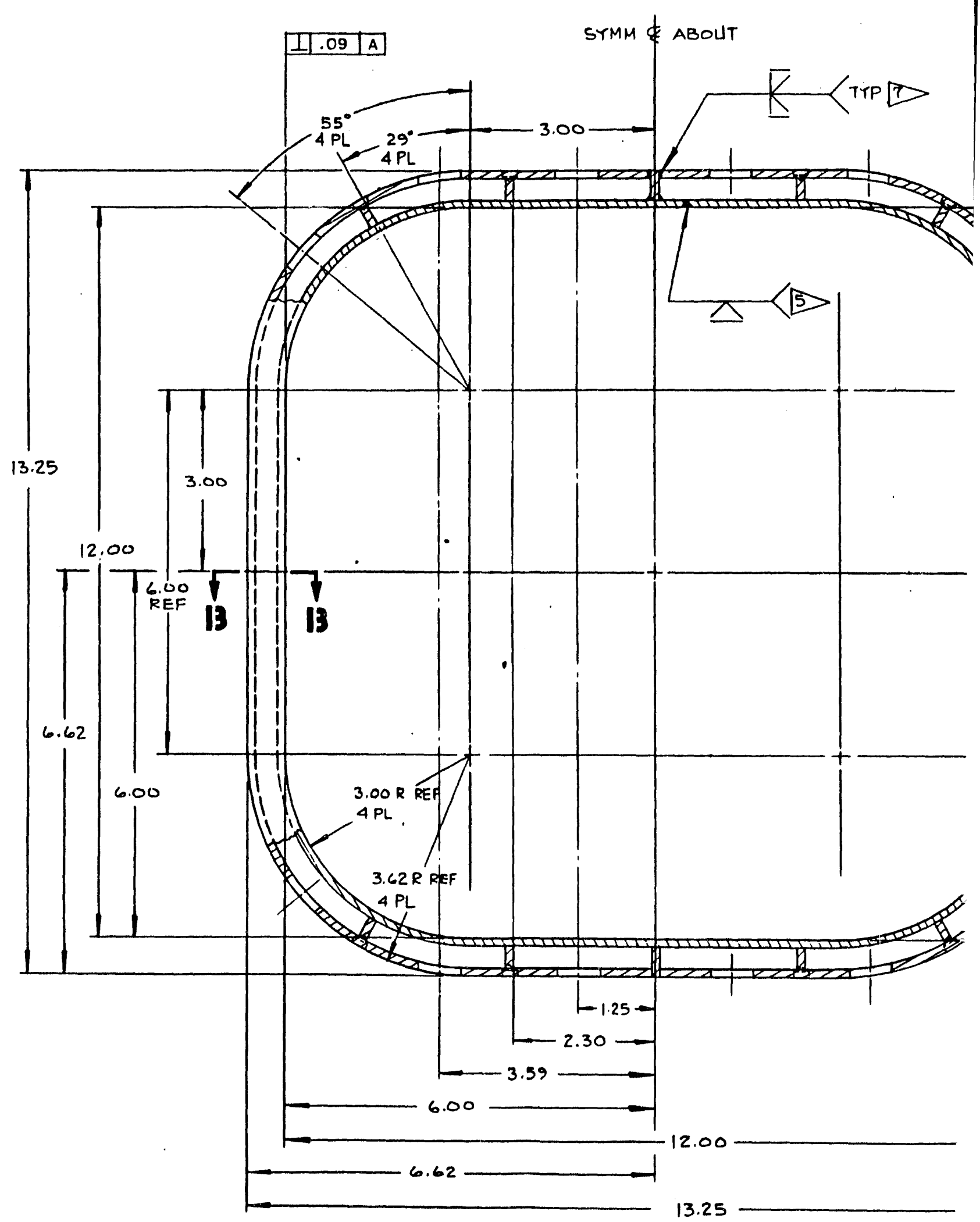

(1) WELDMENT 
1. ALL SURFACES OF ALL COMPONENTS TO BE SOLVENT CLEANED TO REMOVE GAEASE, OIL, AND OTHER CONTAMINANTS. USE NO SOLVENTS OR CUTTING OILS CONTAININB SILICON.

CHL ORINE, OR SULFUR IALCOHOL OR ACETONE ARE ACCEPTABLEI.

2. WELD PER MIL - W -2219

3. WELD SYMBOLS PER AWS A2.4.

4 INSPECT AND CLEAN PER GA SPEC 4.2106.15TS,

5 IDENTIFY IN AREA NOTED PER GA SPEC 3-4005.4TS, TYPE II.

5 MATERIAL: INCONEL 600 PER AMS 5599.

7 MATCH DRILL $\varnothing .390$ HOLE FOR 3/8* BOLTS IN ITEMS AND 23 USING ITEMS 10 THROUGH 17. AND 24 TAPPED HOLES.

3 GRIND BOLTS FLUSH TO TOP SURFACE OF KKARB TILES AFTER ASSE MBL $Y$.

9 ORIENTATE CLIP. ITEM 34, AS REQUiRED.

D AVAILABLE FROM: KAISER AEROTEC
SAN LEANDRO, CA. 94577

II AVAILABLE FROM: BERG IWINFAED M.I INC P.O. BOX B EAST ROCKAWAY, N.Y. 11518 PHONE $15161596 \cdot 1700$

2 ALION ITEM'S 19, 20, \& 21 PRIOR TO WELDING. 3 SILVER PLATE .002 THK OVER A NICKEL
STRIKE. REF: AMS 2410
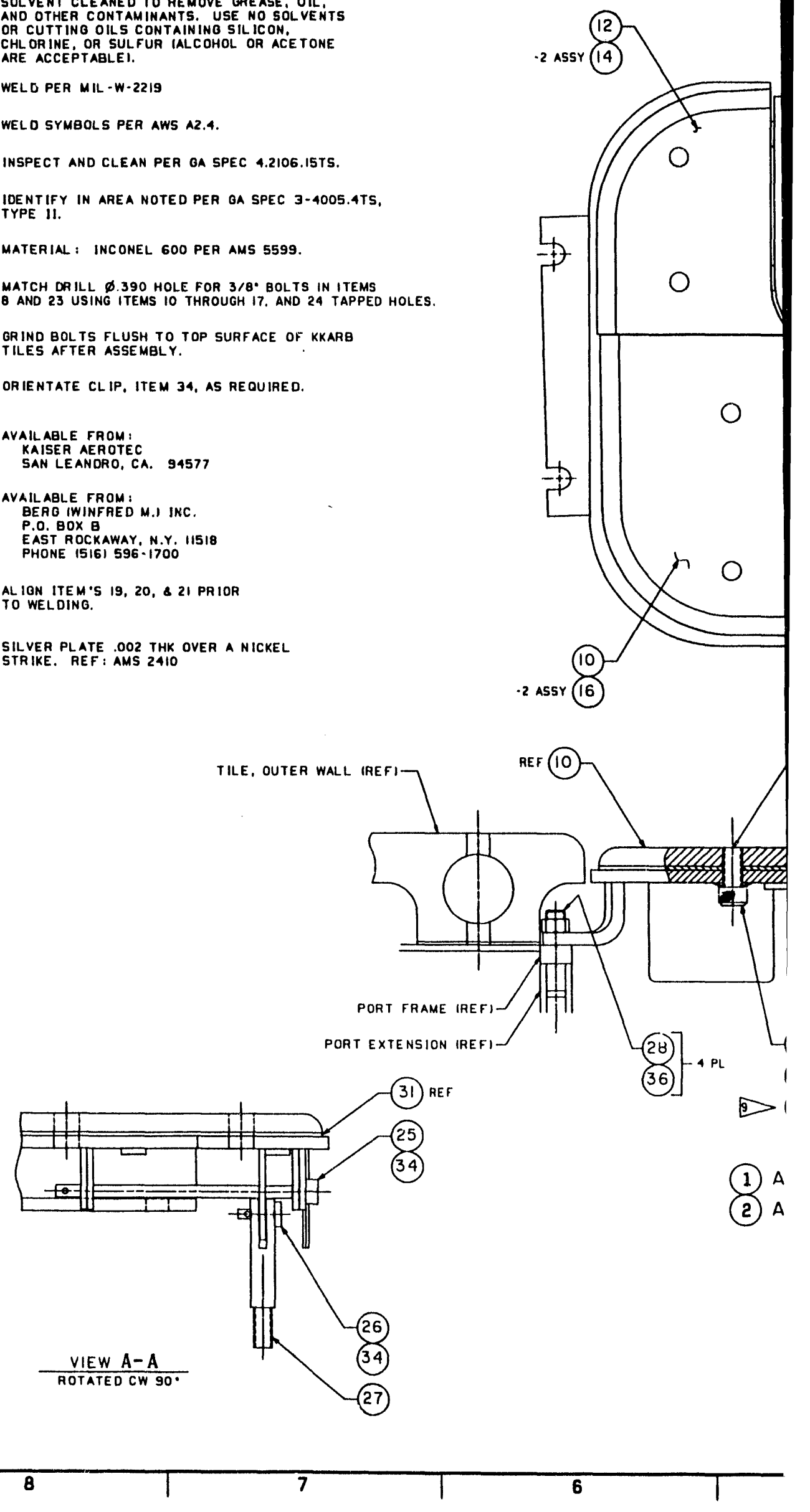

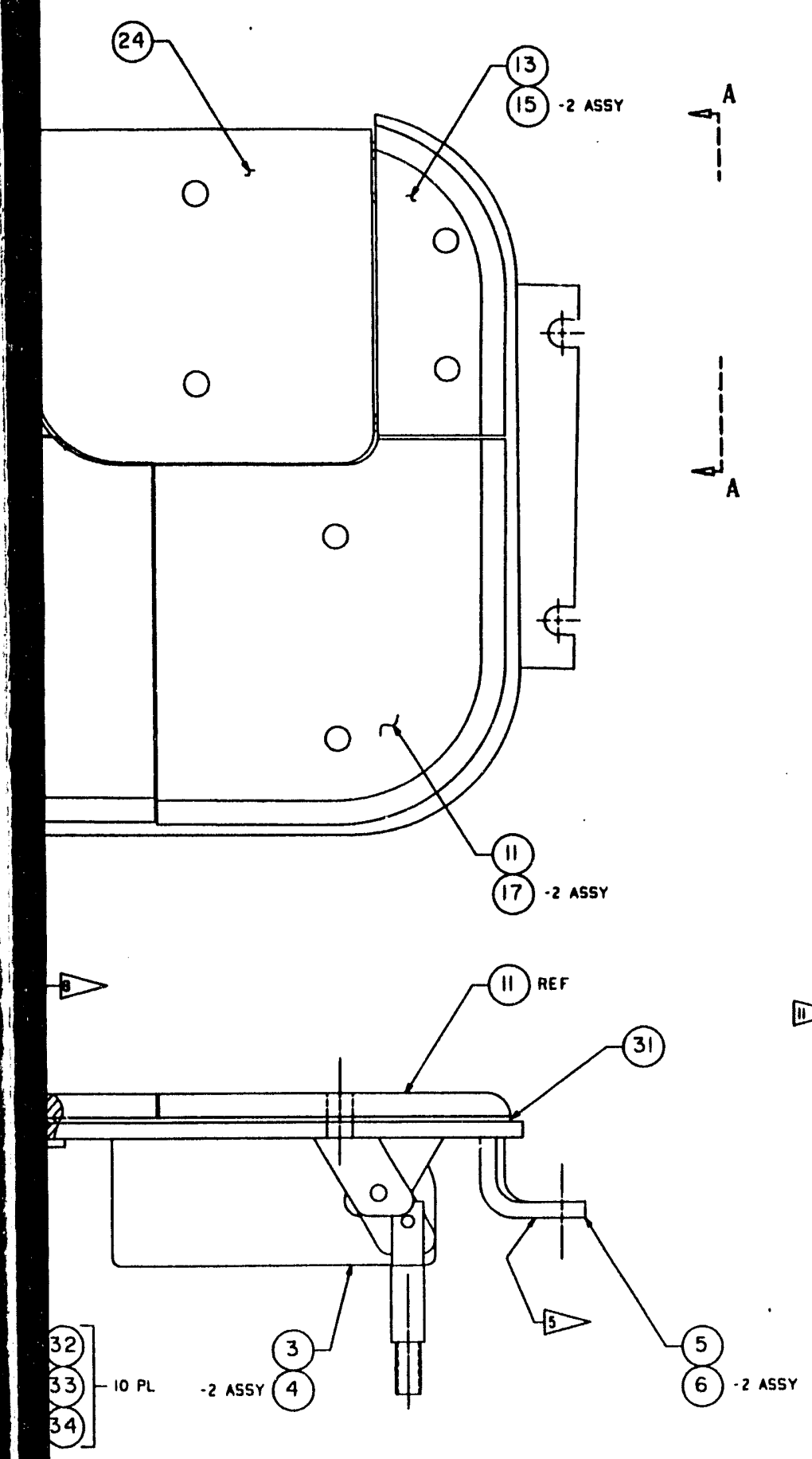

SSEMBLY (SHOWN)

SSEMBLY

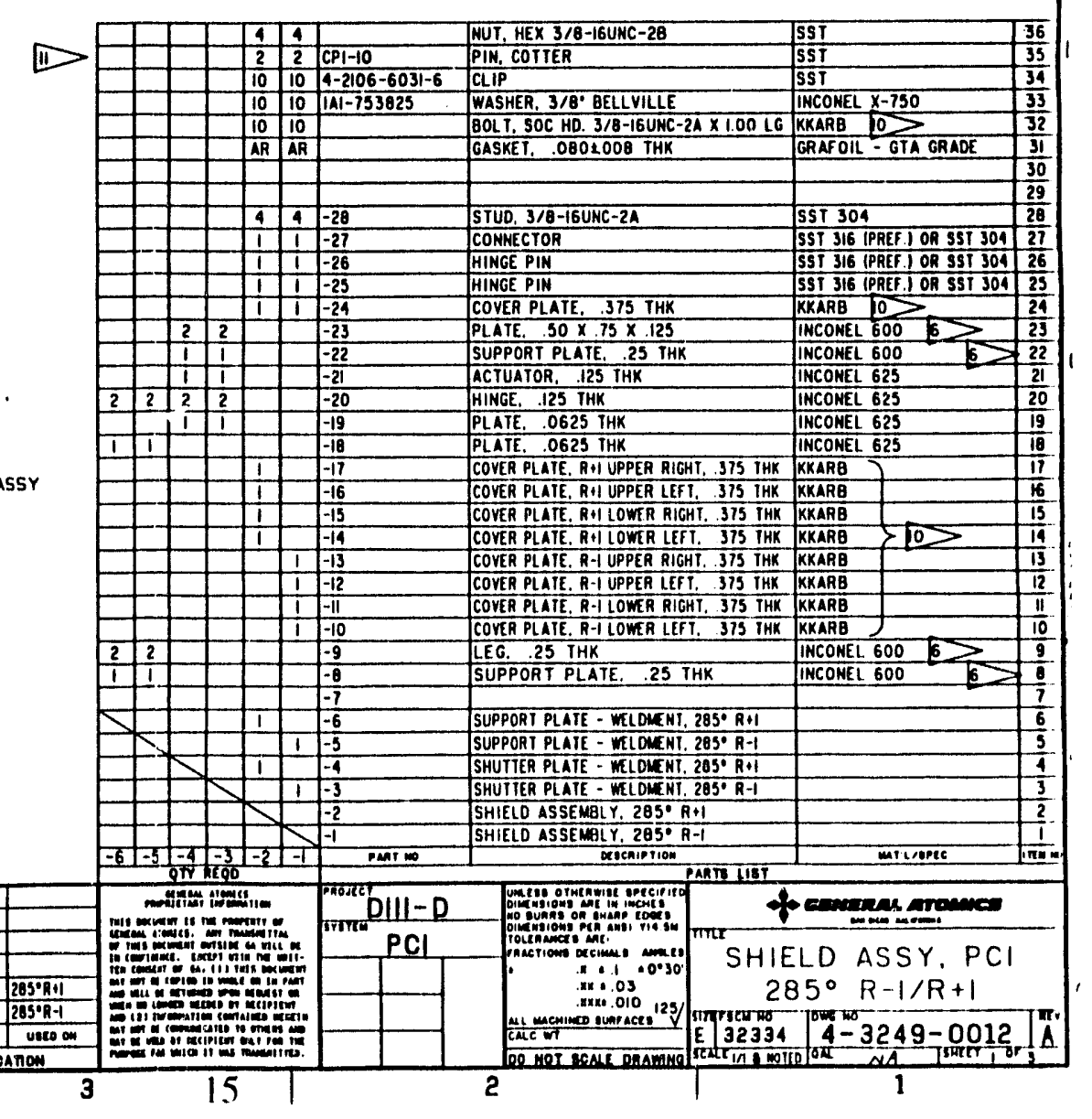




\section{APPENDIX B}

\section{PROPERTIES OF K-KARB CARBON-CARBON COMPOSITE MATERIAL}

The graphite composite material used in this application contains a two dimensional carbon fiber arrangement. The fibers are oriented in groups of parallel rows oriented at roughly a 60-degree angle, in layers of woven sheet arrangements throughout the thickness of the graphite panel. This produces a material whose compressive strength perpendicular to the face of the panel is on the order of $15 \mathrm{ksi}$. The compressive strength parallel to the fibers varies between six and ten ksi depending on the relative panel dimensions. Other data supplied by the manufacturer (Kaiser Aerotech) are as follows:

Thermal Conductivity (Perpenducular to Panel)

Coefficient of Thermal Expansion

Tensile Strength (In Plane of Panel)

Flexural Strength

Interlaminar Shear

Specific Gravity

Electrical Resistivity
4.0 BTU/hr-ft-degree F.

(At 250 degrees $\mathrm{F}$.)

$2.0 \times 10^{-6} \mathrm{in} / \mathrm{in}$-degree $\mathrm{F}$.

(At 700 degreees F.)

$1.4 \times 10^{6}$ psi (By Actual Test)

$12,500 \mathrm{psi}$

1500 psi

1.45

$15 \pm 1 \times 10^{-4}$ Ohm-in 


\section{APPENDIX C}

\section{PROCEDURE FOR INSTALLATION OF SHIELD PLATES R+1 AND R-1-285 DEGREES}

1. The shield plates are assumed to have been assembled with the K-Karb tiles and graphoil pads affixed and torqued to the proper level. The K-Karb bolts (10 per shield plate) shall be safety locked.

2. The shutter assembly has been installed and the hinge pins cotter keyed, except for the attachment of the shutter actuator rod.

3. The shutter actuator rod cannot be attached to the shutter until the shield plates have been fully installed on the port.

4. Insert the shutter actuator adapter into the threaded receiver on the end of the actuator rod in the port. Turn in a few turns to hold the adapter.

5. Prepare the welding template for welding of the studs to the port frame.

a. Thread the four special anchor nuts onto the four short studs. (Stud length $=0.70^{\prime \prime}$ )

b. Attach the studs to the template with standard 3/8-24 nuts. (These nuts need engage only three or four threads on the stud).

c. The special anchor nuts should be on the underside of the template.

d. Maximize the amount of stud which protrudes below the special anchor nut. This provides maximum access for tack welding the studs to the port frame.

6. Add or remove graphite wall tiles around the periphery of the port so that all tiles are installed except those on both sides of the port immediately above and below the horizontal centerline of the port. (Four tiles should be missing, two on each side of the port). 


\section{APPENDIX C (Continued)}

7. Position the shield plate on the port. Adjust the shield to obtain approximately equal spacing between the shield and the adjacent wall tiles on all sides of the shield.

8. Using a transfer punch, mark the port frame at two hold-down stud locations on opposite sides of the shield plate.

9. Remove the shield plate and position the template with the studs attached so that the studs line up as close as possible with the punch mark locations set in step eight above.

10. Carefully hold the template in this position and tack weld all four studs to the edge of the port frame.

11. Loosen and remove all four of the nuts which hold the template to the studs, then remove the template. Unscrew and remove the four special anchor nuts from the studs. Retain these special nuts for installation of the other shield plate.

12. Complete welding the studs to the port frame.

13. Install the shield plate on the port and secure with $3 / 8-24$ nuts. Torque to $35 \mathrm{ft}-\mathrm{lbs}$.

14. Attach the shutter to the actuator rod using a silver plated hinge pin, and secure the pin with a cotter key.

15. Cycle the shutter with the pneumatic operator and verify that proper open and close positions are achieved. Turn the actuator rod attachment in or out as required to obtain satisfactory operation.

16. Repeat the above procedure steps 1 through 15 for the second shield plate. 

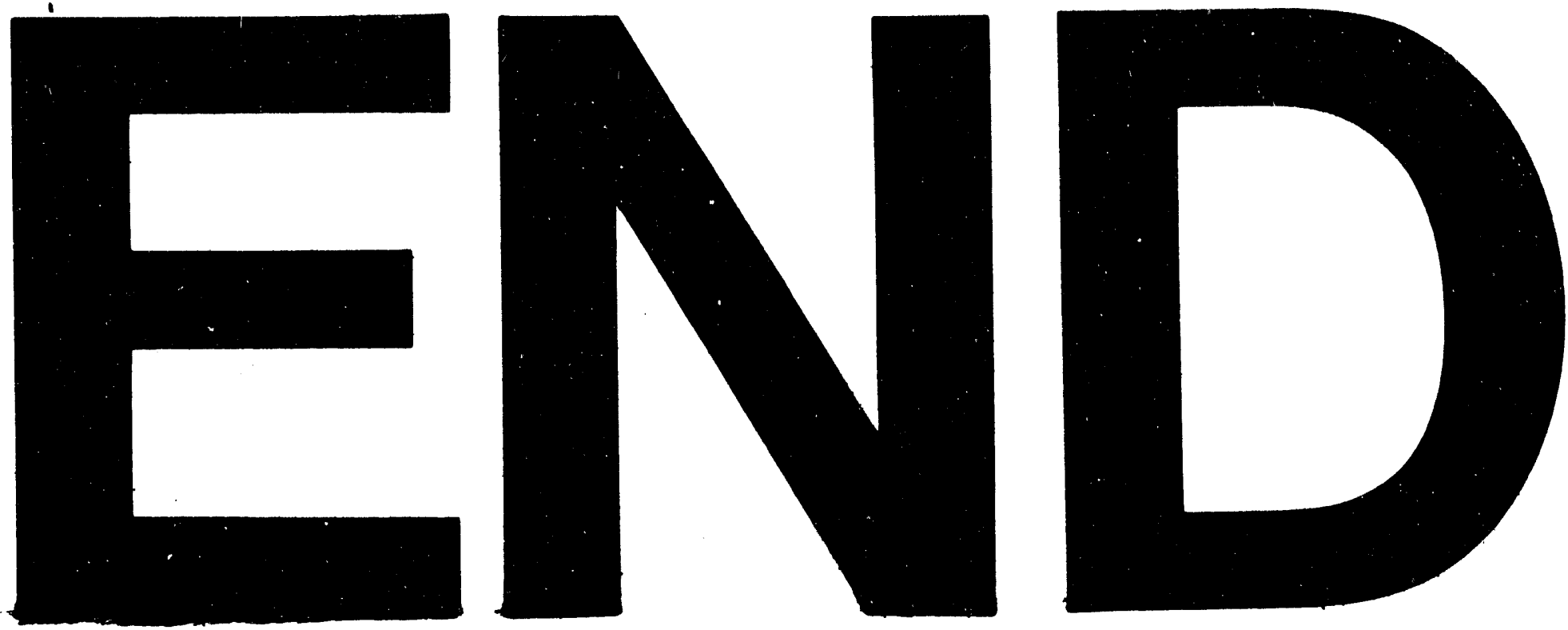

7
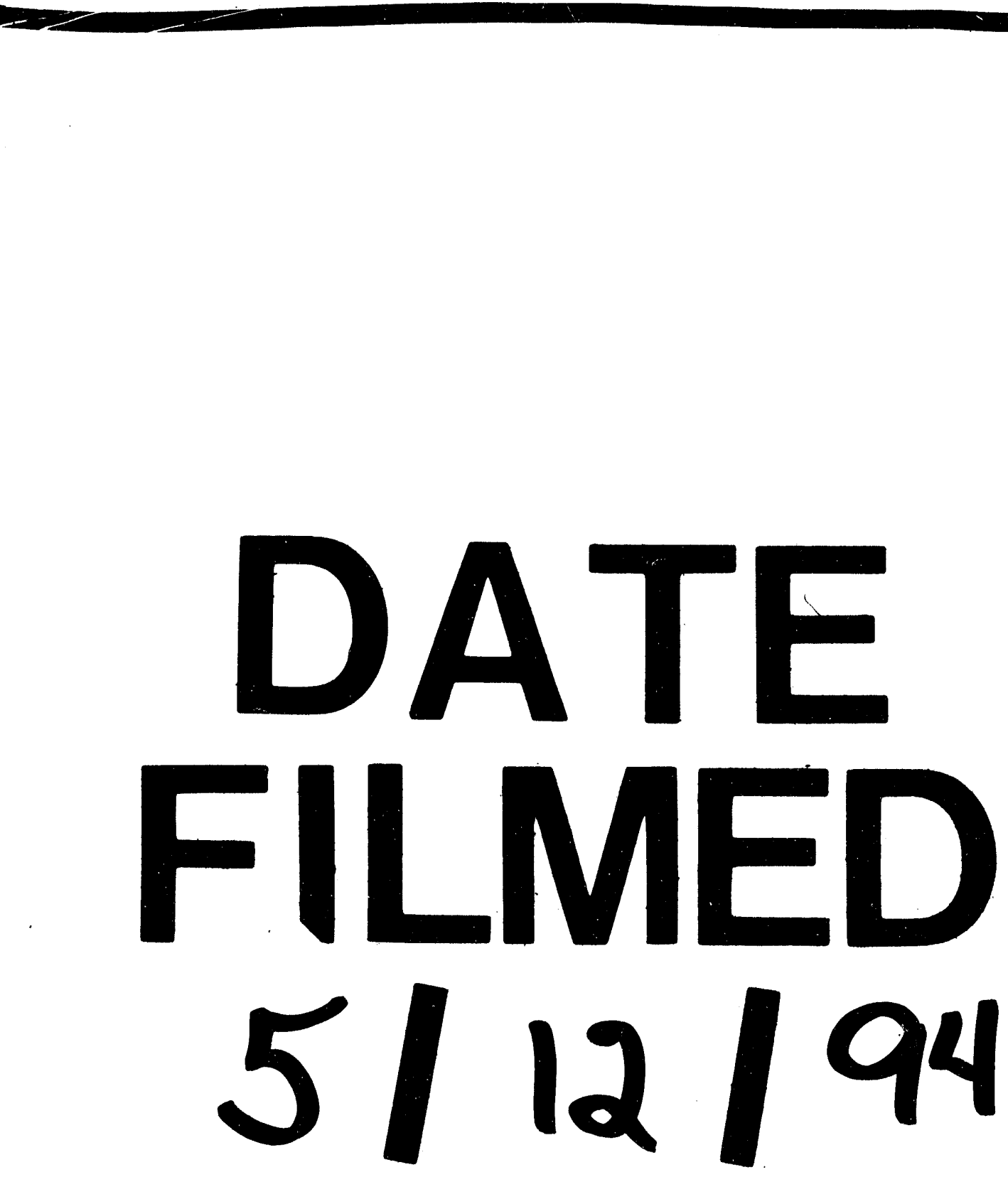
